\title{
A phase II study of stereotactic body radiation therapy for low-intermediate-high-risk prostate cancer using helical tomotherapy: dose-volumetric parameters predicting early toxicity
}

\author{
Victor A. Macias ${ }^{1}{ }^{*}$, Manuel L. Blanco ${ }^{1}$, Inmaculada Barrera ${ }^{2}$ and Rafael Garcia ${ }^{3}$ \\ ${ }^{1}$ Radiation Oncology Department, Salamanca University Hospital, Salamanca, Spain \\ ${ }^{2}$ Department of Statistics, University of Salamanca, Salamanca, Spain \\ ${ }^{3}$ Radiation Oncology Department, CyberKnife Unit, IMO Group, Madrid, Spain
}

Edited by:

Alan Jay Katz, Flushing Radiation

Oncology Services, USA

\section{Reviewed by:}

Rachelle Lanciano, Delaware County Memorial Hospital, USA

Josephine Kang, Flushing Radiation

Oncology Services, USA

*Correspondence:

Victor A. Macias, Oncología

Radioterápica, Hospital Universitario

de Salamanca, Paseo de San Vicente,

182, Salamanca 37007, Spain

e-mail: victormaciash@gmail.com
Endpoint: To assess early urinary (GU) and rectal (GI) toxicities after helical tomotherapy Stereotactic body radiation therapy (SBRT), and to determine their predictive factors.

Methods: Since May 2012, 45 prostate cancer patients were treated with eight fractions of 5.48 (low risk, 29\%) or $5.65 \mathrm{~Gy}$ (intermediate-high risk, $71 \%$ ) on alternative days over 2.5 weeks. The exclusion criteria were Gleason score 9-10, PSA $>40 \mathrm{ng} / \mathrm{mL}, \mathrm{cT3b}-4$, IPSS $\geq 20$, and history of acute urinary retention. During the follow-up, a set of potential prognostic factors was correlated with urinary or rectal toxicity.

Results: The median follow-up was 13.8 months ( $2-25$ months). There were no grade $\geq 3$ toxicities. Acute grade $2 \mathrm{GU}$ complications were found in a $22.7 \%$ of men, but in $2.3 \%$ of patients at 1 month, $0 \%$ at 6 months, and $0 \%$ at 12 months. The correspondent figures for grade $2 \mathrm{Gl}$ toxicities were $20.4 \%$ (acute), $2.3 \%$ (1 month), $3.6 \%$ (6 months), and $5 \%$ (12 months). Acute $\mathrm{Gl}$ toxicity was significantly correlated with the rectal volume $\left(>15 \mathrm{~cm}^{3}\right)$ receiving $28 \mathrm{~Gy}$, only when expressed as absolute volume. The age ( $>72$ years old) was a predictor of GI toxicity after 1 month of treatment. No correlation was found, however, between urinary toxicity and the other analyzed variables. IPSS increased significantly at the time of the last fraction and within the first month, returning to the baseline at sixth month. Urinary-related quality of life (IPSS question 8 score), it was not significantly worsen during radiotherapy returning to the baseline levels 1 month after the treatment. At 12 months follow-up patient's perception of their urinary function improved significantly in comparison with the baseline.

Conclusion: Our scheme of eight fractions on alternative days delivered using helical tomotherapy is well tolerated. We recommend using actual volume instead of percentual volume in the treatment planning, and not to exceed $15 \mathrm{~cm}^{3}$ of rectal volume receiving $\geq 25 \mathrm{~Gy}$ in order to diminish acute $\mathrm{Gl}$ toxicity.

Keywords: prostate cancer, stereotactic body radiation therapy, tomotherapy, predictors toxicity, common toxicity criteria, IPSS

\section{INTRODUCTION}

The Canadian Association of Radiation Oncology defines stereotactic body radiation therapy (SBRT) as the precise delivery of highly conformal and image-guided hypofractionated externalbeam radiotherapy, delivered in a single or few fraction(s) to an extracraneal body target with doses at least biologically equivalent to a radical course when given over a protracted conventionally (1.8-3.0 Gy/fraction) fractionated schedule (1). The American Society for Radiation Oncology has recently stated that "data supporting the use of SBRT for prostate cancer have matured to a point where SBRT could be considered an appropriate alternative for selective patients with low to intermediate-risk disease."
There are not yet available data from controlled randomized trials comparing SBRT with moderate hypofractionated or normofractionated radiation therapy. Most of the SBRT studies are phase II prospective trials using a dedicated robotic linear accelerator (Cyberknife, Accuracy, Sunnyvale, CA, USA) (2-11). The most common prescriptive dose is five fractions of $7-7.5 \mathrm{~Gy}$ (12). Given the prostate cancer radiobiology, tumor cells receive biologically equivalent doses as high as $85-91 \mathrm{~Gy}(\alpha / \beta 1.5)$, which ensures a biochemical recurrence free survival over $90 \%$ at $3-5$ years for low and intermediate risk. Acute and late grade $\geq 3$ events are rare in these selected studies. Recently, a few phase II trials on prostate SBRT using non-robotic linear accelerators have been published 
with limited numbers of patients and short follow up. There is a limited experience on this approach (13-17). The theoretical advantages are that the homogeneous dose distribution and the slightly protracted scheme may decrease toxicity. We are reporting an analysis of the predictors for early toxicity after an 8-fraction regimen on alternative days delivered by helical tomotherapy in low-intermediate-high-risk prostate cancer patients.

\section{MATERIALS AND METHODS \\ PATIENTS}

This is a single institution phase II trial study approved in 2012 by the Salamanca University Hospital Institutional Review Board. The main purpose was to study early and late side effects of SBRT hypofractionated radiotherapy for prostate cancer with helical tomotherapy. It was designed to enroll 107 patients, assuming a loss of $10 \%$.

The selection of patients, treatment planning, and delivery were described in a previous article (18). Briefly, patients selected to be included in the study had histologically confirmed adenocarcinoma of the prostate cT1-3a, Gleason score $<8$, and initial PSA $<20 \mathrm{ng} / \mathrm{mL}$. Since May 2013 patients over 70 years old with Gleason score 8 and PSA $<10 \mathrm{ng} / \mathrm{mL}$ or PSA $20-40 \mathrm{ng} / \mathrm{mL}$ and Gleason score $\leq 7$ were also selected. Exclusion criteria were clinical stage cT3b-4, involved lymph nodes or distant metastases on imaging, prior pelvic radiotherapy, International Prostate Symptom Score System (IPSS) $>20$, or history of acute urinary retention. Patients were regrouped by version 3.2012 NCCN guidelines (low risk: PSA $<10$ and Gleason sum of 6 and clinical stage T1c-T2a, intermediate risk: PSA 10-20 or Gleason sum of 7 or clinical stage T2b-c, high-risk: PSA $>20$ or Gleason sum 8-10 or clinical stage T3a).

\section{SIMULATION AND TREATMENT PLANNING}

An anti-flatulence diet and mild oral laxatives were taken 2 weeks before simulation CT until the end of radiotherapy treatment. Bladder was filled with $250 \mathrm{ml}$ contrast material through a urinary catheter at the time of the simulation CT. Intraprostatic fiducials were not implanted. The clinical target volume (CTV) included the prostate and the proximal seminal vesicles (at the point where the seminal vesicles separate). A contour was drawn around the prostate gland with margins of about $2-5 \mathrm{~mm}$, depending on the prostate cancer risk group $(19,20)$. CTV to PTV margins were based on recommendations of two series with image guidance with implanted fiducials $(21,22)$. CTV was expanded $6 \mathrm{~mm}$ in the craniocaudal direction, $3 \mathrm{~mm}$ posteriorly, $4-5 \mathrm{~mm}$ laterally, and anteriorly up to symphysis pubis (about $7-10 \mathrm{~mm}$ ). The rectum was contoured as a solid organ up to $1 \mathrm{~cm}$ above and below the PTV-containing sections. The posterior half of the rectum was also contoured on each CT slice (23). Not more than the $2 \%$ of the volume should receive $\geq 37$ Gy. This auxiliary volume was created to help make a sharp dose gradient on the anterior rectum. Figure 1 shows the dose distribution on a typical patient. The prescription dose was 43.84 or 45.2 Gy to the PTV delivered in eight fractions on alternative days, which corresponds to a tumor equivalent dose at 2 Gy/fraction (EQD2) of approximately 87.4 or 92.3 Gy for NCCN low risk and intermediate-high risk, respectively, assuming a $\alpha / \beta$ ratio of $1.5 \mathrm{~Gy}$. Correspondent figures for late-responding normal tissues $(\alpha / \beta$ of $3 \mathrm{~Gy})$ are 74.3 and $78.2 \mathrm{~Gy}$, respectively. Dose was

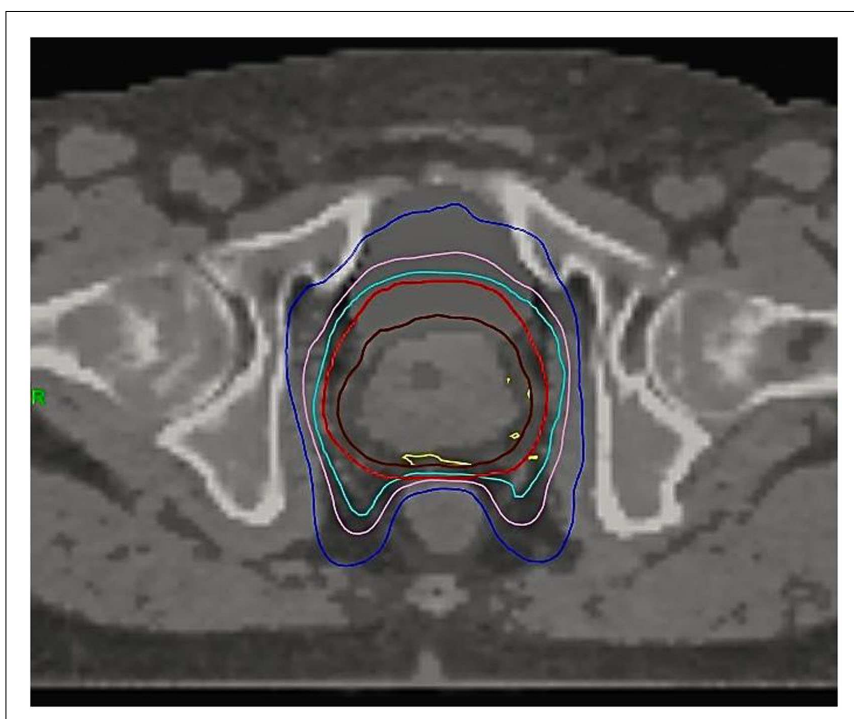

FIGURE 1 | Dose distribution on a typical patient. CTV (brown), PTV (red), 95\% isodose (light blue), $37 \mathrm{~Gy}$ isodose (pink), $28 \mathrm{~Gy}$ isodose (dark blue), $103 \%$ isodose (yellow).

prescribed to $95 \%$ of PTV. All cases were contoured, reviewed, and approved by a single physician (Victor A. Macias).

\section{TREATMENT DELIVERY}

Megavoltage CT images (MVCT) were acquired before each fraction using the on-board scanner of the Tomotherapy unit and were co-registered to the simulation CT using automatic fusion of bony anatomy and soft tissue. The registration was further manually adjusted to account for inter-fractional motion. We ensured that the prostate was within the $95 \%$ isodose, minimizing at the same time the volume of rectum irradiated. Endorectal balloons were not used. Patients measured the volume they urinated just after each treatment fraction in order to have feedback information to help keep their bladder volume between 200 and $300 \mathrm{~cm}^{3}$. The median of the eight measurements was also recorded (MVU). During radiotherapy, the patients were prescribed with $0.4 \mathrm{mg}$ tamsulosin and corticosteroid enema (fluocinilone).

\section{HORMONAL THERAPY}

Intermediate-high-risk patients were prescribed with an androgen deprivation therapy ( $\mathrm{AD}$ ) before being sent to Radiation Oncology, which consisted of one injection of 6-month gonadotropinreleasing hormone agonist plus $50 \mathrm{mg} /$ day bicalutamide for the first month. AD was, therefore, neoadjuvant and concomitant to radiation therapy.

\section{FOLLOW-UP}

Acute toxicity collects complications during radiotherapy and the following 2 weeks. Toxicity was prospectively documented at follow-up visits at month 1,6,12,18, and 24 after the completion of SBRT using the common terminology criteria for adverse events (CTCAE) version 4.0. PSA and total testosterone were obtained during the visits. IPSS questionnaires were filled out by patients before radiotherapy, at the last fraction and during the follow-up 
visits. IPSS question eight (Q8) refers to the patient's perceived urinary-related quality of life. Biochemical failure was defined as a rise of $2 \mathrm{ng} / \mathrm{mL}$ over nadir.

\section{STATISTICAL ANALYSIS}

All statistical analyses were performed with IBM SPSS software version 21.0 and some graphics were made with Microsoft Excel version 14.3.9 for Mac. The following variables were studied as potential prognostic factors of acute toxicity: age, Charlson Comorbidity Index, risk group, AD, total dose, basal IPSS, CTV, PTV, rectal volume, bladder volume, and the median of the volume of urine measured immediately after each of the eight fractions (MVU) and finally, the amount of rectum or bladder (absolute or percentage volume), which receives the dose levels used in the treatment planning $(\geq 43, \geq 40, \geq 37, \geq 34$, and $\geq 28 \mathrm{~Gy})$. These variables were also correlated with urinary or rectal toxicity during follow up. Sample medians and ranges were used to describe continuous variables, except age, whose mean and SD was used instead. For qualitative variables, frequencies, and/or percentages were used. It was examined whether the variables were correlated with urinary or rectal toxicity along the follow-up. Student's $t$ test or ANOVA test were used with age, while U-Mann Whitney, or Kruskal-Wallis tests were used with the other quantitative variables. Receiver operating characteristic curve (ROC curve) analysis provided us the statistical methods to determine the cut-off value for a variable with the highest sensitivity and specificity in order to classify patients without toxicity versus with toxicity. The chisquare test was used with qualitative variables. Student's $t$-test and Wilcoxon test were used to assess differences in ongoing PSA and quality of life scores (total IPSS score and Q8) in comparison to the baseline. As reported by Chen et al. (24), the minimally important difference (MID) in IPSS score was defined as a change of one-half SD from the baseline.

\section{RESULTS \\ DESCRIPTION OF OUR SERIES}

In the period starting on May 2012 up to April 2014, 45 prostate cancer patients were treated following the SBRT protocol at the Salamanca University Hospital. Table 1 shows patient characteristics. By NCCN classification, 71\% belonged to the intermediate or high-risk group. Eight of these were elderly men with Gleason score 8 and PSA $<10 \mathrm{ng} / \mathrm{mL}$ or PSA $20-40 \mathrm{ng} / \mathrm{mL}$ and Gleason score $\leq 7$. Most patients $(80 \%)$ had a Charlson Comorbidity Index of $0-1$. Thirty-two patients received $45.2 \mathrm{~Gy}$ at $5.65 \mathrm{~Gy} /$ fraction and 13 patients received $43.84 \mathrm{~Gy}$ at $5.48 \mathrm{~Gy} /$ fraction. Plans were homogeneous by design, with doses ranking from 95 to $103 \%$ within the PTV. The $98 \%$ isodose covered at least $95 \%$ of the PTV (median 99.2\% of the PTV). A summary of the dose-volume histogram is shown in Table 2. The median volume of MVU is $260 \mathrm{ml}$ (range 125-400), suggesting bladder volume through the course of radiotherapy is not very different from the bladder volume contoured on the simulation CT.

The median follow-up is 13.8 months (range $2-25$ months). All patients but one were able to complete the treatment. That patient died in an accident after the sixth fraction. Thirty-five patients received neoadjuvant-concomitant AD for 6-26 months (median 6 months). The eight elderly high-risk selected patients above
Table 1 | Patient, tumor, and treatment characteristics.

\begin{tabular}{|c|c|c|}
\hline Age & Mean \pm SD (years) & $70.40 \pm 7.19$ \\
\hline \multirow[t]{4}{*}{ Charlson comorbidity index } & 0 & $26 / 45(57.8 \%)$ \\
\hline & 1 & $10 / 45(22.2 \%)$ \\
\hline & 2 & $8 / 45(17.8 \%)$ \\
\hline & 4 & $1 / 45(2.2 \%)$ \\
\hline \multirow[t]{5}{*}{ IPSS pre-RT } & Median (range) & $5(0-14)$ \\
\hline & $0-4$ & $17 / 45(37.8 \%)$ \\
\hline & $5-9$ & $16 / 45(35.6 \%)$ \\
\hline & $10-14$ & $11 / 45(24.4 \%)$ \\
\hline & NA & $1 / 45(2.2 \%)$ \\
\hline \multirow[t]{4}{*}{ PSA } & Median (ng/mL) & 9 \\
\hline & $<10$ & $25 / 45(55.6 \%)$ \\
\hline & $10-20$ & $17 / 45(37.6 \%)$ \\
\hline & $>20$ & $3 / 45(6.7 \%)$ \\
\hline \multirow[t]{5}{*}{ cT stage } & $1 c$ & $19 / 45(42.2 \%)$ \\
\hline & $2 a$ & $4 / 45(8.9 \%)$ \\
\hline & $2 b$ & $6 / 45(13.3 \%)$ \\
\hline & $2 c$ & $2 / 45(6.7 \%)$ \\
\hline & За & $13 / 45(28.9 \%)$ \\
\hline \multirow[t]{2}{*}{ Pelvic MRI } & Yes & $16 / 45(35.6 \%)$ \\
\hline & No & $29 / 45(64.4 \%)$ \\
\hline \multirow[t]{4}{*}{ Gleason score } & 5 & $1 / 45(2.2 \%)$ \\
\hline & 6 & $22 / 45(48.9 \%)$ \\
\hline & 7 & $17 / 45(37.8 \%)$ \\
\hline & 8 & $5 / 45(11.1 \%)$ \\
\hline \multirow[t]{3}{*}{ NCCN risk group } & Low & $13 / 45(28.9 \%)$ \\
\hline & Intermediate & $17 / 45(37.8 \%)$ \\
\hline & High & 15/45 (33.3\%) \\
\hline \multirow[t]{2}{*}{ Androgen deprivation (AD) } & Yes & $35 / 45(77.8 \%)$ \\
\hline & No & $10 / 45(22.2 \%)$ \\
\hline Total dose (Gy) & Median & 45.2 \\
\hline Dose/fraction (Gy) & Median & 5.65 \\
\hline Irradiation time (s) & Median (range) & 513 (384-695) \\
\hline AD duration (months) & Median (range) & $6(6-26)$ \\
\hline
\end{tabular}

mentioned, also received neoadjuvant-concomitant AD, instead of the neoadjuvant-concomitant-adjuvant AD for 2-3 years, which is the standard for high-risk patients in our institution. Six out of 13 low-risk patients were prescribed $\mathrm{AD}$ before being sent to Radiation Oncology.

\section{BIOCHEMICAL FAILURE}

So far, there is one intermediate-risk patient that met the biochemical failure definition at 17 months post-treatment. PSA rose to $3.34 \mathrm{ng} / \mathrm{mL}$ after a nadir level of $0.44 \mathrm{ng} / \mathrm{mL}$, however, it fell to $2.09 \mathrm{ng} / \mathrm{mL} 2$ months later. The upcoming PSA tests will serve to distinguish true biochemical recurrence from a PSA bounce. For the whole series, pre-treatment total PSA levels ranged from 1.2 to $34 \mathrm{ng} / \mathrm{mL}$ with a median value of $9 \mathrm{ng} / \mathrm{mL}$. At 1 month after SBRT, the median PSA value was $0.1 \mathrm{ng} / \mathrm{mL}(0.010-9.800)$ 
with a median total serum testosterone level of $19 \mathrm{ng} / \mathrm{dL}$, while at 12 months after radiotherapy the correspondent figures were $0.16 \mathrm{ng} / \mathrm{mL}(0.002-3.000)$ and $200 \mathrm{ng} / \mathrm{dL}$.

\section{TOXICITY}

No grade 3 or 4 toxicities were encountered. Maximum urinary and rectal complications are reported in Table 3. The acute urinary toxicities were dysuria (18 grade 1 and 5 grade 2 ), nocturia (13 grade 1 and 3 grade 2), urinary frequency (9 grade 1 and 3 grade 2), retention (4 grade 1 and 2 grade 2, one of which had acute retention), and finally urgency (3 grade 1 and 2 grade 2 ). The acute intestinal complications were proctitis/hemorrhoidal pain during bowel movements ( 8 grade 1, 2 grade 2 ), frequency with normal stool consistency (7 grade 1, 1 grade 2 ), bleeding ( 7 grade 1, 2 grade 2 ), tenesmus (3 grade 1, 4 grade 2 ), incontinence (4 grade 1, 1 grade 2 ), abdominal pain (5 grade 1 ), and diarrhea (2 grade 1 and 1 grade 2 ).

\section{PREDICTORS OF TOXICITY}

Regarding the small number of grade 2 toxicity events, we grouped the patients into without (grade 0 ) or with toxicity (grade 1 or 2 ).

Table 2 | Summary of dose-volume histogram data.

\begin{tabular}{lccc}
\hline & Median & Min & Max \\
\hline CTV $\left(\mathrm{cm}^{3}\right)$ & 113.70 & 53.00 & 209.90 \\
PTV $\left(\mathrm{cm}^{3}\right)$ & 201.0 & 61.20 & 339.70 \\
Rectum $\left(\mathrm{cm}^{3}\right)$ & 43.60 & 24.70 & 89.00 \\
Bladder $\left(\mathrm{cm}^{3}\right)$ & 224.00 & 19.50 & 346.60 \\
Penile bulb $\left(\mathrm{cm}^{3}\right)$ & 6.70 & 3.60 & 13.00 \\
PTV V98\% $(\%)$ & 99.15 & 95.00 & 100.00 \\
PTV D2\% (Gy) & 46.40 & 44.20 & 47.30 \\
Rectum V43Gy $\left(\mathrm{cm}^{3}\right)$ & 2.7 & 0.1 & 12.70 \\
Rectum V40Gy $\left(\mathrm{cm}^{3}\right)$ & 5.25 & 1.20 & 71.40 \\
Rectum V37Gy $\left(\mathrm{cm}^{3}\right)$ & 7.45 & 3.60 & 22.60 \\
Rectum V34Gy $\left(\mathrm{cm}^{3}\right)$ & 9.6 & 4.9 & 28.3 \\
Rectum V28Gy $\left(\mathrm{cm}^{3}\right)$ & 14.65 & 8.3 & 45 \\
Bladder V43Gy $(\%)$ & 15.5 & 8.00 & 26.70 \\
Bladder V40 Gy $(\%)$ & 20.20 & 10.30 & 36.90 \\
Bladder V37Gy $(\%)$ & 25.40 & 13.50 & 46.20
\end{tabular}

Any dose-volume variable expressed as a percentage was correlated with toxicity; nevertheless, some of them were correlated when expressed as absolute volume (cubic centimeter). The probability of having acute intestinal toxicity was statistically associated to the volume of rectum receiving $\geq 28 \mathrm{~Gy}$ ( $p=0.029$ ). In our sample, beyond $15 \mathrm{~cm}^{3}$, the probability of having acute intestinal toxicity is over $60 \%$ (test efficacy 0.7045 ). Fifteen of the 45 patients had a rectal volume of $>15 \mathrm{~cm}^{3}$ receiving that dose. In contrast, only five patients did not meet the dose limit actually used in the treatment planning (the percentage of rectal volume receiving $\geq 28 \mathrm{~Gy}$ should be less than $40 \%$ ). In our trial, the age was a predictor of GI toxicity after a month of treatment $(p=0.0005)$. Under 72 years old, the probability of having GI toxicity is below $12 \%$ (test efficacy 0.63 ). No correlation was found between urinary toxicity and the other analyzed variables.

\section{QUALITY OF LIFE}

Seventy-three percentage of the patients had mild to moderate lower urinary tract symptoms prior to SBRT with a mean initial IPSS of 6.25 (range, 0-14, SD 3.75) (Figure 2). That score increased significantly at the time of the last fraction $(p=0.000)$ and at 1 -month follow-up $(p=0.021)$, returning to baseline at 6 months $(p=0.196)$. One month post-treatment, however, mean IPSS was barely above the MID (MID level 8.125). Urinary-related quality of life (Figure 3), derived from the Q8 score, worsened not significantly during radiotherapy $(p=0.107)$ returning to the baseline levels at 1 month after the treatment. At 12 months follow-up patient's perception of their urinary function improved significantly $(p=0.006)$ compared with baseline.

\section{DISCUSSION}

Presently, a handful of prospective studies using SBRT for prostate cancer have been published, which have shown successful outcomes with low toxicity profiles $(2-8,13-17)$. In an attempt to overcome the problem of the small number of patients included in each study, a consortium was formed to pool the available data of phase II prospective trials from eight institutions that used Cyberknife (9). A total of 1100 patient were enrolled with a median follow-up of 36 months. The 5 -year biochemical relapse free survival rate was 95,84 , and $81 \%$ for low-, intermediate-, and high-risk patients, respectively, supporting that Cyberknife SBRT

Table 3 | Prevalence of urinary and intestinal toxicities at each follow-up

\begin{tabular}{|c|c|c|c|c|c|c|c|c|}
\hline & \multicolumn{4}{|c|}{ Urinary toxicity } & \multicolumn{4}{|c|}{ Intestinal toxicity } \\
\hline & Grade 0 & Grade 1 & Grade 2 & Grade 3 & Grade 0 & Grade 1 & Grade 2 & Grade 3 \\
\hline & $25 \%$ & $52.27 \%$ & $22.72 \%$ & $0 \%$ & $38.63 \%$ & $40.90 \%$ & $20.45 \%$ & $0 \%$ \\
\hline At 1 month & $32 / 43$ & $1 / 43$ & $1 / 43$ & $0 / 43$ & $36 / 43$ & $7 / 43$ & $1 / 43$ & $0 / 43$ \\
\hline \multirow[t]{2}{*}{ At 6 months } & $23 / 28$ & $5 / 28$ & $0 / 28$ & $0 / 28$ & $22 / 28$ & $5 / 28$ & $1 / 28$ & $0 / 28$ \\
\hline & $82.14 \%$ & $17.85 \%$ & $0 \%$ & $0 \%$ & $78.57 \%$ & $17.86 \%$ & $3.57 \%$ & $0 \%$ \\
\hline \multirow[t]{2}{*}{ At 12 months } & $16 / 20$ & $4 / 20$ & $0 / 20$ & $0 / 20$ & $13 / 20$ & $6 / 20$ & $1 / 20$ & $0 / 20$ \\
\hline & $80 \%$ & $20 \%$ & $0 \%$ & $0 \%$ & $65 \%$ & $30 \%$ & $5 \%$ & $0 \%$ \\
\hline
\end{tabular}




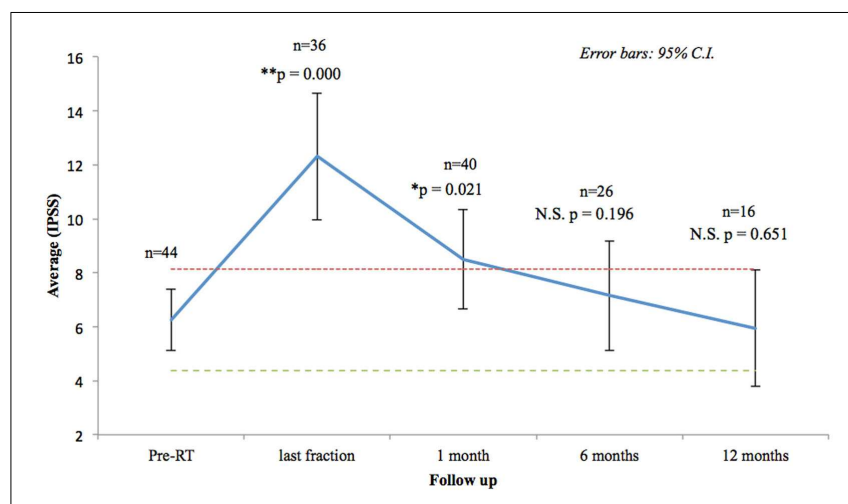

FIGURE 2 | Urinary quality of life (IPSS questions 1-7). The scores range from 0 to 35 with higher values representing worsening urinary symptoms. Numbers above each time point indicate the number of observations contributing to the average. The thresholds for minimally important clinical differences (MID) are marked with dashed lines.

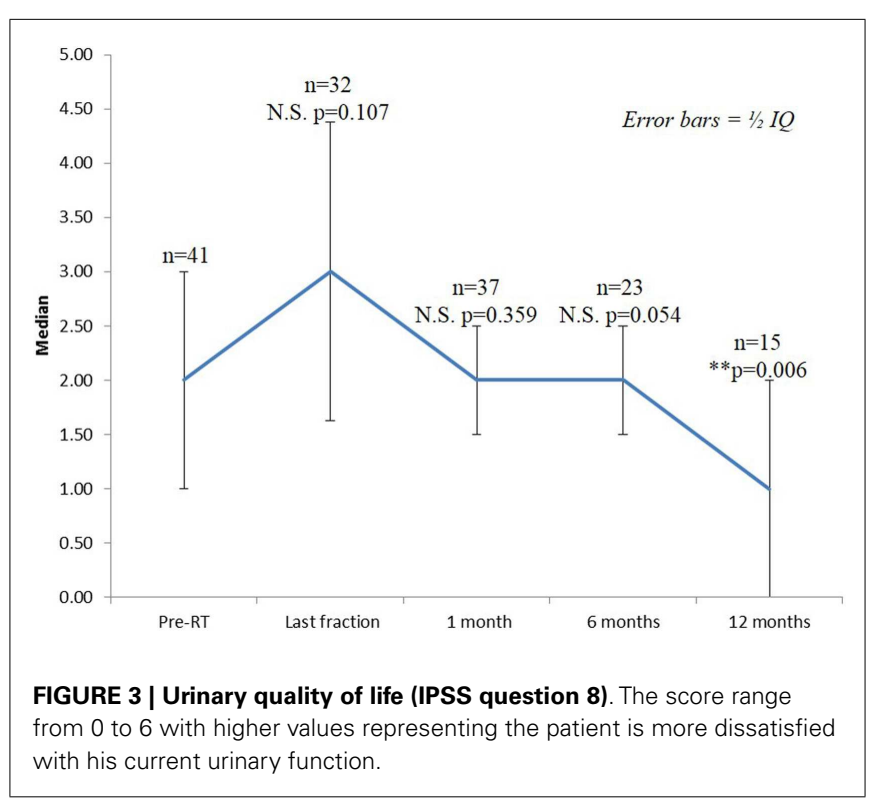

can be considered as an appropriate therapeutic option for selected patients. However, there is a limited experience on prostatic SBRT delivered by conventional linear accelerator or helical tomotherapy. Emerging data from single institutional series suggest that this approach can achieve similar low rates of grade $\geq 3$ early toxicity compared with robotic SBRT (Table 4). Conventional LINACs protocols usually use a more protracted overall treatment time (alternate days or weekly fractions), reflecting the concern about acute tolerance and consequential late effects. In a series of 64 patients who received five fractions of $7.25 \mathrm{~Gy}$, every-other-day treatments resulted in substantially less frequent grade 1-2 urinary toxicity ( 17 vs. $56 \%, p=0.007$ ) and less frequent grade $1-2$ rectal toxicity ( 5 vs. $44 \%, p=0.001$ ) compared with daily treatments (10). Our study was designed to administer the treatment fractions every-other-day over 2.5 weeks, while delivering to the late-responding normal tissues the same biologically equivalent dose as the standard 20-fraction hypofractionated scheme used in our institution. In order to obtain a homogeneous dose distribution, avoiding hot spots over $105 \%$ in the periurethral zone of the prostate, the full dose was prescribed to $95 \%$ of PTV, instead of $70-80 \%$ isodose usually used in HDR-like SBRT. With the aim of reducing urinary symptoms, the Georgetown University Hospital changed his Cyberknife SBRT protocol to limit the prescription isodose from $\geq 70$ to $\geq 80 \%$ and the maximum prostatic urethral dose from 133 to $110 \%$. In their opinion, the relatively high incidence of acute urinary grade 3 observed in their series was caused by the highly heterogeneous dose distribution inside the prostate, with hot spots up to $40 \%$ above the prescribed dose, and also by the patient selection, as they treated the patients not suitable for brachytherapy (large volume, bad flow, high IPSS, TURP, or abdominal surgery, hip joint prostheses) (2).

Inter-fraction changes in prostate shape are not uniform throughout the length of the gland. A distended rectum can lead to an anteroposterior shift in the cranial aspect of the gland and not in the apex. As a result, it is sometimes the case that a correction compromises the adequate coverage of the anterior part of the CTV. To avoid this, the PTV has been expanded anteriorly to the pubic bone. This, together with the overestimation of prostate gland volumes using traditional CT-based planning, since MRI was only used for prostate cancer staging, results in larger CTV/PTV in our series compared with Cyberknife studies.

A limitation of the study is the lack of assessment and management of intrafraction motion. The deviation of prostate intrafraction motion distribution is a function of stool/gas volume. While the effectiveness of dietary intervention, oral laxatives and rectal enema is controversial (25-29), intrafraction motion is significantly reduced by endorectal balloons (30), specially with longer treatment times. An adequate patient preparation protocol before treatment and the daily use of endorectal balloon can effectively stabilized prostate motion for $90 \%$ of the fractions using a 3$\mathrm{mm}$ internal margin (31). Additionally, patients treated with a water-filled endorectal balloon reported significantly less urgency and incontinence, while their treatment plans showed significantly lower doses to the anal wall, rectal wall and all pelvic floor muscles (32). In our institution the inter-fraction prostate displacement is taken into account by MVCT images with soft tissue registration without fiducials. With manual registration of planning CT and $\mathrm{kV}$ cone-beam CT (CBCT) without implanted markers the interobserver variability results in errors of $2-3 \mathrm{~mm}$ (33). CBCT with implanted markers can decrease inter-observer variability within $2 \mathrm{~mm}$ compared with soft tissue alignment (34). So, consideration needs to be given to margin design at each institution when using soft tissue matching due to the above described increased inter-observer variability.

We observed that the urinary function, measured on the AUA/IPSS scale, recovered as in other non-robotic (16) and Cyberknife trials (35-37). The median AUA score increased slightly at the 1-month follow-up and then returned to baseline values at 3-month and subsequent follow-up intervals. Madsen et al. (16) also found that after 12 months of follow-up, more than a half of the patients reported improvement of their scores compared to baseline. King et al. reported quality of life prospectively measured among 864 patients from phase II clinical trials of SBRT 
Table 4 | Acute toxicity SBRT in Cyberknife and non-robotic series

\begin{tabular}{|c|c|c|c|c|c|}
\hline & GU grade $2(\%)$ & GU grade $3(\%)$ & GI grade $2(\%)$ & GI grade $3(\%)$ & Scheme \\
\hline \multicolumn{6}{|l|}{ CYBERKNIFE } \\
\hline Aluwini et al. (2) & 15 & 8 & 12 & 2 & 38 Gy/4 consecutive fx (SIB $44 \mathrm{~Gy} / 4 \mathrm{fx}$ in DIL) \\
\hline Bolzicco et al. (3) & 12 & 0 & 18 & 0 & 35 Gy/5 consecutive $\mathrm{fx}$ \\
\hline Friedland et al. (4) & - & 0.9 & - & 0.9 & 35-36 Gy/5 consecutive $\mathrm{fx}$ \\
\hline Kang et al. (5) & 13.6 & 0 & 9.1 & 0 & 32-36 Gy/4 consecutive $\mathrm{fx}$ \\
\hline Katz et al. (6) & $4-4.7$ & 0 & $3.6-4$ & 0 & 35-36.25 Gy/5 consecutive $\mathrm{fx}$ \\
\hline Oliai et al. (7) & 19 & 4 & 4 & 0 & 36.25-37.5 Gy/5 consecutive fx \\
\hline \multicolumn{6}{|c|}{ NON-ROBOTIC SBRT ${ }^{a}$} \\
\hline Alongi et al. (13) & 40 & 0 & 10 & 0 & $35 \mathrm{~Gy} / 5 \mathrm{fx}$ on alternate days \\
\hline Boike et al. (14) & $7-33$ & 0 & $0-27$ & 0 & $45-50$ Gy/5 fx separated $\geq 36 \mathrm{~h}$ \\
\hline Loblaw et al. (15) & 19 & 1 & 10 & 0 & $35 \mathrm{~Gy} / 5 \mathrm{fx}$ once a week \\
\hline Madsen et al. (16) & 21 & 2 & 13 & 0 & $33.5 \mathrm{~Gy} / 5$ consecutive $\mathrm{fx}$ \\
\hline Menkarios et al. (17) & 31 & 5 & 14 & 0 & $45 \mathrm{~Gy} / 9$ fx once a week \\
\hline Current study & 22.7 & 0 & 20.4 & 0 & 43.84-45.20 Gy/8 fx on alternate days \\
\hline
\end{tabular}

${ }^{a}$ Radiotherapy technique: volumetric modulated arc therapy (13), step and shoot IMRT (14-16), 3DCRT (17), helical tomotherapy (current study).

$S I B$, simultaneous integrated boost; DIL, dominant intraprostatic lesion.

(11). For urinary QOL, a significant but modest decline was also most notable within the first 3 months, which had mostly recovered by 6 months, remained stable thereafter. For those patients with poorer urinary function at baseline (i.e., worst 25th or fifth percentile), a gradual improvement in urinary QOL was in fact observed beginning 6 months after treatment and progressing to better than baseline function over the 6-years follow-up. No differences were seen with the addition of $\mathrm{AD}$ or as a function of patient age. A similar trend was seen for bowel QOL.

Low evidence is available on the predictors for acute toxicity after prostate SBRT. We observed that the volume of rectum receiving $\geq 28 \mathrm{~Gy}$ is correlated with acute intestinal toxicity. Kim et al. enrolled 91 patients on a dose-escalation (from 45 to $50 \mathrm{~Gy}$ in five fractions) phase I/II study (38). According to our results, they observed that grade $\geq 2$ acute rectal toxicity was significantly correlated with more than $50 \%$ of the rectal wall receiving $\geq 24 \mathrm{~Gy}$. In their opinion, minimal vascular/stromal injury is likely to occur at that dose level, allowing an adequate blood supply to the recruited stem cells leading to an effective repair of the injury, provided that less than half the rectal wall receives $\geq 24 \mathrm{~Gy}$. We have observed that the volume of rectum receiving a particular radiation dose was an independent predictor of rectal toxicity when using actual volume rather than percent volume. Others authors have had the same findings and are then currently using actual rectal volume when setting up planning constraints (39).

In our series, $71 \%$ of the patients are intermediate-high risk. Most SBRT trials have only included low-risk cases due to the concern that the tight margins required to limit the normal tissue doses may not be adequate to treat the microscopic disease. Ju et al. (37) reported that for the majority of their patients, treated with Cyberknife SBRT, the coverage of the 33-Gy isodose line (76 Gy EQD2, $\alpha / \beta$ 1.5) is more than $5 \mathrm{~mm}$ beyond the prostate, excluding posterior direction, where it is $\leq 3 \mathrm{~mm}$ in most cases. In our study, one half of the seminal vesicles were included within the CTV, and the PTV extended at least $5 \mathrm{~mm}$ from prostate gland.
In any patient, more than $95 \%$ of the PTV received the $98 \%$ of the prescribed dose (equivalent to $92 \mathrm{~Gy}$ EQD2, $\alpha / \beta$ 1.5). We therefore believe that our approach should effectively eradicate the microscopic extraprostatic disease in high-risk prostate cancer patients.

\section{CONCLUSION}

Our scheme of eight fractions on alternate days (EQD2 $=87-$ $92 \mathrm{~Gy}, \alpha / \beta$ 1.5) delivered using helical tomotherapy is well tolerated. We observe an impact on urinary quality of life at the end of the radiotherapy treatment and 1 month later, with subsequent recovery to baseline at 3 months follow-up. In order to decrease acute toxicity, we recommend $15 \mathrm{~cm}^{3}$ as the cut-off of the rectal volume not to exceed $28 \mathrm{~Gy}(\mathrm{EQD} 2=48.4 \mathrm{~Gy}, \alpha / \beta 3)$. However, the rectal volume receiving that dose, expressed as a percentage, was not correlated with the intestinal toxicity. That supports using actual volume rather than percent volume in the treatment planning. The use of endorectal balloon catheters would help us to reduce intrafraction movement, reduce moderate doses in lateral and posterior rectal walls and to determine the position of the anterior rectal wall at daily MVCT. A comparison between this 8fraction series and our contemporary 20 -fraction series, with total doses equivalent for late-responding tissues, is ongoing.

\section{ACKNOWLEDGMENTS}

Victor A. Macias is supported by a scientific grant (GRS 903/A/14) from the Public Health Care System of Castile and Leon.

\section{REFERENCES}

1. Sahgal A, Roberge D, Schellenberg D, Purdie TG, Swaminath A, Pantarotto J, et al. The Canadian Association of Radiation Oncology scope of practice guidelines for lung, liver and spine stereotactic body radiotherapy. Clin Oncol (R Coll Radiol) (2012) 24(9):629-39. doi:10.1016/j.clon.2012.04.006

2. Aluwini S, van Rooij P, Hoogeman M, Kirkels W, Kolkman-Deurloo I-K, Bangma C. Stereotactic body radiotherapy with a focal boost to the MRI-visible tumor as monotherapy for low- and intermediate-risk prostate cancer: early results. Radiat Oncol Lond Engl (2013) 8:84. doi:10.1186/1748-717X-8-84 
3. Bolzicco G, Favretto MS, Satariano N, Scremin E, Tambone C, Tasca A. A single-center study of 100 consecutive patients with localized prostate cancer treated with stereotactic body radiotherapy. BMC Urol (2013) 13:49. doi:10.1186/1471-2490-13-49

4. Friedland JL, Freeman DE, Masterson-McGary ME, Spellberg DM. Stereotactic body radiotherapy: an emerging treatment approach for localized prostate cancer. Technol Cancer Res Treat (2009) 8(5):387-92. doi:10.1177/ 153303460900800509

5. Kang J-K, Cho CK, Choi CW, Yoo S, Kim M-S, Yang K, et al. Image-guided stereotactic body radiation therapy for localized prostate cancer. Tumori (2011) 97(1):43-8. doi:10.1700/611.7137

6. Katz AJ, Santoro M, Diblasio F, Ashley R. Stereotactic body radiotherapy for localized prostate cancer: disease control and quality of life at 6 years. Radiat Oncol Lond Engl (2013) 8(1):118. doi:10.1186/1748-717X-8-118

7. Oliai C, Lanciano R, Sprandio B, Yang J, Lamond J, Arrigo S, et al. Stereotactic body radiation therapy for the primary treatment of localized prostate cancer. J Radiat Oncol (2013) 2(1):63-70. doi:10.1007/s13566-012-0067-2

8. Freeman DE, King CR. Stereotactic body radiotherapy for low-risk prostate cancer: five-year outcomes. Radiat Oncol Lond Engl (2011) 6:3. doi:10.1186/1748717X-6-3

9. King CR, Freeman D, Kaplan I, Fuller D, Bolzicco G, Collins S, et al. Stereotactic body radiotherapy for localized prostate cancer: Pooled analysis from a multiinstitutional consortium of prospective phase II trials. Radiother Oncol (2013) 109:217-21. doi:10.1016/j.radonc.2013.08.030

10. King CR, Brooks JD, Gill H, Presti JC Jr. Long-term outcomes from a prospective trial of stereotactic body radiotherapy for low-risk prostate cancer. Int J Radiat Oncol Biol Phys (2012) 82(2):877-82. doi:10.1016/j.ijrobp.2010.11.054

11. King CR, Collins S, Fuller D, Wang P-C, Kupelian P, Steinberg M, et al. Healthrelated quality of life after stereotactic body radiation therapy for localized prostate cancer: results from a multi-institutional consortium of prospective trials. Int J Radiat Oncol Biol Phys (2013) 87(5):939-45. doi:10.1016/j.ijrobp. 2013.08.019

12. Arcangeli S, Scorsetti M, Alongi F. Will SBRT replace conventional radiotherapy in patients with low-intermediate risk prostate cancer? A review. Crit Rev Oncol Hematol (2012) 84(1):101-8. doi:10.1016/j.critrevonc.2011.11.009

13. Alongi F, Cozzi L, Arcangeli S, Iftode C, Comito T, Villa E, et al. Linac based SBRT for prostate cancer in 5 fractions with VMAT and flattening filter free beams: preliminary report of a phase II study. Radiat Oncol Lond Engl (2013) 8(1):171. doi:10.1186/1748-717X-8-171

14. Boike TP, Lotan Y, Cho LC, Brindle J, DeRose P, Xie X-J, et al. Phase I dose-escalation study of stereotactic body radiation therapy for low- and intermediate-risk prostate cancer. J Clin Oncol (2011) 29(15):2020-6. doi:10. 1200/JCO.2010.31.4377

15. Loblaw A, Cheung P, D'Alimonte L, Deabreu A, Mamedov A, Zhang L, et al. Prostate stereotactic ablative body radiotherapy using a standard linear accelerator: toxicity, biochemical, and pathological outcomes. Radiother Oncol (2013) 107(2):153-8. doi:10.1016/j.radonc.2013.03.022

16. Madsen BL, Hsi RA, Pham HT, Fowler JF, Esagui L, Corman J. Stereotactic hypofractionated accurate radiotherapy of the prostate (SHARP), 33.5 Gy in five fractions for localized disease: first clinical trial results. Int J Radiat Oncol Biol Phys (2007) 67(4):1099-105. doi:10.1016/j.ijrobp.2006.10.050

17. Menkarios C, Vigneault É, Brochet N, Nguyen DHA, Bahary J-P, Jolicoeur M, et al. Toxicity report of once weekly radiation therapy for low-risk prostate adenocarcinoma: preliminary results of a phase I/II trial. Radiat Oncol Lond Engl (2011) 6:112. doi:10.1186/1748-717X-6-112

18. Macias VA, Blanco ML, Perez-Romasanta LA. Initial experience with stereotactic body radiation therapy for localized prostate cancer using helical tomotherapy. Clin Transl Oncol (2014) 16(4):380-5. doi:10.1007/s12094-013-1089-y

19. Teh BS, Bastasch MD, Wheeler TM, Mai WY, Frolov A, Uhl BM, et al. IMRT for prostate cancer: defining target volume based on correlated pathologic volume of disease. Int J Radiat Oncol Biol Phys (2003) 56(1):184-91. doi:10.1016/S0360-3016(03)00085-3

20. Macias V. CTV margins in prostate cancer irradiation. In regard to Teh et al.: IMRT for prostate cancer: defining target volume based on correlated pathologic volume of disease. Int J Radiat Oncol Biol Phys (2004) 59(1):320-1. doi:10.1016/j.ijrobp.2004.01.008

21. Meijer GJ, de Klerk J, Bzdusek K, van den Berg HA, Janssen R, Kaus MR, et al. What CTV-to-PTV margins should be applied for prostate irradiation? Four-dimensional quantitative assessment using model-based deformable image registration techniques. Int J Radiat Oncol Biol Phys (2008) 72(5):1416-25. doi:10.1016/j.ijrobp.2008.03.005

22. Wu Q, Ivaldi G, Liang J, Lockman D, Yan D, Martinez A. Geometric and dosimetric evaluations of an online image-guidance strategy for 3D-CRT of prostate cancer. Int J Radiat Oncol Biol Phys (2006) 64(5):1596-609. doi:10.1016/j.ijrobp. 2005.12.029

23. Boehmer D, Kuczer D, Badakhshi H, Stiefel S, Kuschke W, Wernecke KD, et al. Influence of organ at risk definition on rectal dose-volume histograms in patients with prostate cancer undergoing external-beam radiotherapy. Strahlenther Onkol (2006) 182(5):277-82. doi:10.1007/s00066-006-1462-7

24. Chen LN, Suy S, Uhm S, Oermann EK, Ju AW, Chen V, et al. Stereotactic Body Radiation Therapy (SBRT) for clinically localized prostate cancer: the Georgetown University experience. Radiat Oncol Lond Engl (2013) 8(1):58. doi:10.1186/1748-717X-8-58

25. Fiorino C, Di Muzio N, Broggi S, Cozzarini C, Maggiulli E, Alongi F, et al. Evidence of limited motion of the prostate by carefully emptying the rectum as assessed by daily MVCT image guidance with helical tomotherapy. Int J Radiat Oncol Biol Phys (2008) 71(2):611-7. doi:10.1016/j.ijrobp.2008.01.048

26. McNair HA, Wedlake L, Lips IM, Andreyev J, Van Vulpen M, Dearnaley D. A systematic review: Effectiveness of rectal emptying preparation in prostate cancer patients. Pract Radiat Oncol (2014) 4(6):437-47. doi: 10.1016/j.prro.2014.06.005. Available from: http://www.practicalradonc.org/ article/S1879850014001660/abstract,

27. Ki Y, Kim W, Nam J, Kim D, Lee J, Park D, et al. Probiotics for rectal volume variation during radiation therapy for prostate cancer. Int J Radiat Oncol Biol Phys (2013) 87(4):646-50. doi:10.1016/j.ijrobp.2013.07.038

28. Nichol AM, Warde PR, Lockwood GA, Kirilova AK, Bayley A, Bristow R, et al. A cinematic magnetic resonance imaging study of milk of magnesia laxative and an antiflatulent diet to reduce intrafraction prostate motion. Int J Radiat Oncol Biol Phys (2010) 77(4):1072-8. doi:10.1016/j.ijrobp.2009.06.005

29. Graf R, Boehmer D, Nadobny J, Budach V, Wust P. Appropriate patient instructions can reduce prostate motion. Radiat Oncol Lond Engl (2012) 7:125. doi:10.1186/1748-717X-7-125

30. Steiner E, Georg D, Goldner G, Stock M. Prostate and patient intrafraction motion: impact on treatment time-dependent planning margins for patients with endorectal balloon. Int J Radiat Oncol Biol Phys (2013) 86(4):755-61. doi:10.1016/j.ijrobp.2013.02.035

31. Wang KK-H, Vapiwala N, Bui V, Deville C, Plastaras JP, Bar-Ad V, et al. The impact of stool and gas volume on intrafraction prostate motion in patients undergoing radiotherapy with daily endorectal balloon. Radiother Oncol (2014) 112(1):89-94. doi:10.1016/j.radonc.2014.05.008

32. Smeenk RJ, Hoffmann AL, Hopman WP, van Lin EN, Kaanders JH. Doseeffect relationships for individual pelvic floor muscles and anorectal complaints after prostate radiotherapy. Int J Radiat Oncol Biol Phys (2012) 83(2):636-44. doi:10.1016/j.ijrobp.2011.08.007

33. Moseley DJ, White EA, Wiltshire KL, Rosewall T, Sharpe MB, Siewerdsen JH, et al. Comparison of localization performance with implanted fiducial markers and cone-beam computed tomography for on-line image-guided radiotherapy of the prostate. Int J Radiat Oncol Biol Phys (2007) 67(3):942-53. doi:10.1016/j.ijrobp.2006.10.039

34. Deegan T, Owen R, Holt T, Fielding A, Biggs J, Parfitt M, et al. Assessment of cone beam CT registration for prostate radiation therapy: Fiducial marker and soft tissue methods. J Med Imaging Radiat Oncol (2014). doi:10.1111/1754-9485.12197

35. King CR, Brooks JD, Gill H, Pawlicki T, Cotrutz C, Presti JC. Stereotactic body radiotherapy for localized prostate cancer: interim results of a prospective phase II clinical trial. Int J Radiat Oncol Biol Phys (2009) 73(4):1043-8. doi:10.1016/j.ijrobp.2008.05.059

36. McBride SM, Wong DS, Dombrowski JJ, Harkins B, Tapella P, Hanscom HN, et al. Hypofractionated stereotactic body radiotherapy in low-risk prostate adenocarcinoma: preliminary results of a multi-institutional phase 1 feasibility trial. Cancer (2012) 118(15):3681-90. doi:10.1002/cncr.26699

37. Ju AW, Wang H, Oermann EK, Sherer BA, Uhm S, Chen VJ, et al. Hypofractionated stereotactic body radiation therapy as monotherapy for intermediaterisk prostate cancer. Radiat Oncol Lond Engl (2013) 8:30. doi:10.1186/1748717X-8-30

38. Kim DWN, Cho LC, Straka C, Christie A, Lotan Y, Pistenmaa D, et al. Predictors of rectal tolerance observed in a dose-escalated phase 1-2 trial of stereotactic body radiation therapy for prostate cancer. Int J Radiat Oncol Biol Phys (2014) 89(3):509-17. doi:10.1016/j.ijrobp.2014.03.012 
39. Kupelian PA, Reddy CA, Carlson TP, Willoughby TR. Dose/volume relationship of late rectal bleeding after external beam radiotherapy for localized prostate cancer: absolute or relative rectal volume? Cancer J Sudbury Mass (2002) 8(1):62-6. doi:10.1097/00130404-200201000-00011

Conflict of Interest Statement: The authors declare that the research was conducted in the absence of any commercial or financial relationships that could be construed as a potential conflict of interest.

Received: 26 August 2014; accepted: 05 November 2014; published online: 26 November 2014.
Citation: Macias VA, Blanco ML, Barrera I and Garcia R (2014) A phase II study of stereotactic body radiation therapy for low-intermediate-high-risk prostate cancer using helical tomotherapy: dose-volumetric parameters predicting early toxicity. Front. Oncol. 4:336. doi: 10.3389/fonc.2014.00336

This article was submitted to Radiation Oncology, a section of the journal Frontiers in Oncology.

Copyright (c) 2014 Macias, Blanco, Barrera and Garcia. This is an open-access article distributed under the terms of the Creative Commons Attribution License (CC BY). The use, distribution or reproduction in other forums is permitted, provided the original author(s) or licensor are credited and that the original publication in this journal is cited, in accordance with accepted academic practice. No use, distribution or reproduction is permitted which does not comply with these terms. 